\title{
Chapter 8 \\ The Capability Approach in Research on Ageing Well at Home for Frail Older People
}

\author{
Synneve Dahlin-Ivanoff, Qarin Lood, Katarina Wilhelmson, Kajsa Eklund, \\ Emmelie Barenfeld, Greta Häggblom-Kronlöf, Theresa Westgård, \\ and Isabelle Andersson Hammar
}

\subsection{Introduction}

Today's highly specialised health and social care is poorly adapted to the comprehensive needs of frail older people (SBU, 2014). This exposes them to avoidable risks such as loss of functional capacities accompanied by health and social care needs, as well as increased premature mortality (Morley et al., 2013). In an attempt to contribute to more equitable research and healthcare services with and for frail older people, this chapter describes the work of the Frail Elderly Support Research Group (FRESH) in relation to the capability approach as a theoretical departure. Frail older people have always been our target group because they are at risk of further deterioration if their needs are not acknowledged (Morley et al., 2013). Frailty can be defined as a state of decreased reserve resistance to stressors as a result of cumulative decline across multiple physiological systems, causing vulnerability to different outcomes, such as falls, hospitalisation, institutionalisation and mortality (Fried et al., 2004; Fried et al., 2001). The prevalence of frailty increases with age and is associated with an elevated risk of adverse health outcomes. Within Europe, the overall prevalence of frailty for people aged 65 years and older is approximately $10 \%$, with the northern countries having lower prevalence than the southern (Clegg et al., 2013). By applying the capability approach to our

\footnotetext{
S. Dahlin-Ivanoff $(\bowtie) \cdot$ Q. Lood $\cdot$ K. Wilhelmson $\cdot$ K. Eklund $\cdot$ E. Barenfeld

G. Häggblom-Kronlöf · T. Westgård · I. Andersson Hammar Institute of Neuroscience and Physiology, Department of Psychiatry and Neurochemistry, Sahlgrenska Academy at the University of Gothenburg, Gothenburg, Sweden

Centre for Ageing and Health - AgeCap, University of Gothenburg,

Gothenburg, Sweden

e-mail: synneve.dahlin-ivanoff@neuro.gu.se; qarin.lood@neuro.gu.se; katarina.wilhelmson@ gu.se; emmelie.barenfeld@neuro.gu.se; greta.haggblom-kronlof@neuro.gu.se; theresa.westgard@neuro.gu.se; isabelle.a-h@neuro.gu.se
} 
interdisciplinary research, we aim to identify and acknowledge the values and freedoms unique to each person. There are few publications addressing how the capability approach could be applied to empirical studies with frail older people (Blasimme, 2017). Therefore, this chapter aims to utilise the capability approach as a theoretical framework for research with and for frail older people, focusing on their opportunities to realise their goal in relation to various contextual factors that may influence them.

The capability approach allows us to identify advantages and disadvantages among different groups of people, since it focuses on social justice and human development. In the context of research on ageing and health, many people are currently disadvantaged due to morbidity and disabilities associated with high age and frailty. For instance, people over 65 in need of home care or other social services face the risk of being given no, or limited, choice with regards to when to get out of bed in the morning, what and when to eat, or when to go outdoors. Such injustices can be captured by the multidimensional capability approach, which seeks to identify constraints in both choice and control based on a person's age, frailty, morbidity and/or disabilities. We work with and for people who are at risk of developing frailty, as well as those who are already frail or very frail. Applying the capability approach to qualitative and quantitative studies in empirical settings, FRESH's research programme 'Ageing well at home', referred to in this chapter, aims to find measures that can support older people to remain living in ordinary housing for as long as possible, in a way that they experience as meaningful and satisfying. We also aim to broaden our understanding of the concept of frailty in general. With its contribution to our understanding of the frailty process and how it may influence people as they age, the capability approach is a fundamental part of all projects, focusing on people's real opportunities to achieve what it is possible for them to achieve, and what they have a reason to value, in relation to the resources they have at hand. Based on mutual respect and the sharing of ideas, we as a research group also apply person-centredness to our research with and for frail older people. This means that we place a high value on human interaction, and every person involved in the research process is regarded as capable of contributing with their experience, knowledge and expertise. Every effort is made to involve a wide range of people with different backgrounds and abilities, and to avoid unjust exclusion from research participation based on assumptions about the abilities of frail older people with various linguistic and cultural backgrounds. In combination with the capability approach, person-centredness allows us to understand how to identify and support what is required for each person to age well at home. Our primary focus is to make sure that older people's voices are heard, but the voices of professionals are also important for the development of support that is feasible to implement in real life. The FRESH research group represents both junior and senior researchers who have a broad set of competences representing different disciplines such as caring science, history, medical science, occupational science and social sciences. The research group has experience of both quantitative and qualitative methods and extensive experience of conducting interprofessional and multidimensional intervention studies (RCT) with frail older people in collaboration with hospitals, primary care, and 
health and social care. In this chapter, we describe the key concepts of the capability approach as applied to our research, and outline a suggestion for how research can use the capability approach to assess and minimise inequalities as experienced by frail older people.

\subsection{A Capability Approach to Ageing Well at Home - Key Concepts for Research}

The capability approach, as described by Sen (1993), is a normative framework that builds on the belief that all people have equal rights to experience health and wellbeing, and that the opportunities to do so should be understood in relation to each person's capabilities (Sen, 1993). Two of the core concepts of the capability approach that are applied to FRESH's research with and for frail older people are capabilities and functionings, the latter not to be confused with functional ability. Functionings in the capability approach are described in relation to people's valuable goals, and capabilities refer to their abilities to realise valuable goals. As the name of the approach suggests, the term 'capabilities' is central to understanding the capability approach, and it is defined as a person's ability to achieve their valuable goals (Sen, 1985). Capabilities are not necessarily associated with something that people do, but refer to their ability to choose between different activities and reach their goals, given the resources and services they have to hand. And whether or not people are able to do and be what they have a reason to value is assessed by functionings, defined as what people are really achieving. We describe capabilities and functionings in more detail in relation to our previous studies below.

\subsection{Capabilities}

Although ageing well at home may be interpreted as an achievement in itself, it is not only influenced by the person's ability to achieve, but also by their freedom to choose from a set of alternative achievements, and that is what is meant by capabilities. According to Sen (1985), capabilities refer to the ability to achieve valuable goals, and this includes the freedom to choose or not to choose between different activities (Sen, 1985). As mentioned in the introductory example of people in need of health and social care, capabilities concern the freedom to choose when and how to go about one's everyday activities. Freedom of choice also refers to the opportunity to choose not to do certain things and, as such, capabilities refer to what people are enabled to do and be, given their circumstances. In relation to FRESH's research programme, such circumstances have been defined and measured by three distinct clinical entities that are causally related: frailty, morbidity and disability. As people age, frailty, morbidity and disability may have a negative impact upon their freedom or opportunity to choose. Each entity, individually, occurs frequently and has 
significant importance clinically. Additionally, old age associates strongly with frailty and, with increasing age, the risk of disability also increases (Reuben, 1998). However, it is important to distinguish between them in order to understand the factors that may affect different people across the life course (Fried et al., 2004), and to take variations in need into account. Even though old age associates strongly with each of frailty, morbidity and disability, they are three different entities that need to be separated in order to be able to identify adequate measures to support frail older people to age well at home.

Frailty is a complex geriatric syndrome, which usually manifests in weight loss, exhaustion, low physical activity, slowness and weakness. Some also advocate that the definition of frailty should be expanded to include additional aspects such as social factors, as well as the physical and social environment (Lally \& Crome, 2007; Hogan et al., 2003). There is evidence, however, for the more physical definition of frailty, mentioned above, as a complex geriatric syndrome (Morley et al., 2013), and this is the definition we have used in our studies to capture the biological ageing process. The frailty indicators (weakness, fatigue, low physical activity, poor balance, slow gait speed, visual impairment and impaired cognition) have been used to identify inequalities in all the FRESH studies (Dahlin-Ivanoff et al., 2010). This information is crucial in order to capture the biological ageing process and enable older people to continue performing the daily activities they want and need to do, in their own home environment, as they age.

Morbidity is estimated using the Cumulative Illness Rating Scale for Geriatrics (CIRS-G) (Linn et al. 1968), a rating instrument of chronic medical illness burden that is used to identify inequality (heart, vascular, hematopoietic, respiratory, eyes, ear, nose, throat and larynx, upper gastrointestinal, lower gastrointestinal, liver, renal, genital-urinary, musculoskeletal, neurological, endocrine and psychiatric illness). This information is of great importance clinically. Research shows that morbidity increases with increasing age (Fabbri et al., 2015) and that susceptibility to disease increases if one is frail (Fulop et al., 2010). Morbidity and frailty thus interact with each other and as a person becomes both frail and has one or more diseases, this can eventually lead to them becoming dependent on other people to support and help them with everyday activities, or to premature death.

Disability is defined by dependence in the activities of daily living, to capture inequality in the outcome of the ability to realise valuable goals. Since the ability to realise valuable goals is the focus in the research programme 'Ageing well at home', we assess dependence in the activities of daily living (cleaning, shopping, transportation, cooking, bathing, dressing, going to the toilet, transferring and feeding (Sonn, 1996)) as the primary outcome measure in all our intervention studies. Dependence is defined as another person being involved in the activity by giving personal or directive assistance. People living with another person are assessed as independent if they can perform the activity when alone. The use of dependence in activities of daily living as the primary outcome measure is strengthened by the fact that older people have defined their health in relation to what they can expect in terms of activity and participation on the basis of the more or less inevitable 
symptoms and diseases that come with old age (Fänge \& Dahlin-Ivanoff, 2009; Ebrahimi et al., 2015; Ebrahimi et al., 2013).

Impaired ability to perform daily activities can be a consequence of morbidity and/or frailty, but different people have different abilities and opportunities, depending on what diseases they have and how frail they are. Our knowledge, gathered from many years of research and clinical work with research on older people's abilities to perform everyday activities, shows that it is more complex than just asking how the person manages, or has managed, their everyday activities. For instance, being in the hands of others, such as home help services, can result in frail older people not being able to perform activities in the way they want to. With increasing frailty, the home may become a place for assistive devices and adaptations, and a workplace for social services and healthcare staff. Having to reorganise their home and the frequent comings and goings of professionals and other people can affect the sense of freedom expressed by frail older people (Dahlin-Ivanoff et al., 2007; Fänge \& Dahlin-Ivanoff, 2009). Moreover, it is not uncommon for there to be a difference between what a person says they do and what they actually do, and between what they can do and what they actually do. In order to make a correct analysis of what the person has done, and how they have done it, we must start with a conversation that is designed as a dialogue between two equal people, who both have valuable knowledge. This means listening to what the other person is saying, and how they are saying it, by setting the person's problems, needs and priorities in the foreground. In a dialogue of this kind, the person in question must be given the opportunity to express what is important to them and how they want things to be. This means that the person is given the opportunity to be involved and self-determining in terms of health and medical care, as well as in their everyday activities.

\subsection{Functionings}

Functionings are described by Sen as what people actually achieve, representing the goals that each person has a reason to value (Sen 1987). Such goals are often influenced by the ageing process. For instance, maintaining engagement in daily life through performing daily activities and personal care has been described as an important goal for older people (Häggblom-Kronlöf et al., 2007; Haak et al., 2007). This performance, however, is influenced by contextual factors, such as the environment in which the older person finds themselves. People tend to create meaning and significance in the spaces and places where they live, and in a study of communitydwelling 99-year-old people (Häggblom-Kronlöf et al., 2007), the participants described seeing themselves as competent, creative and proud because they were able to manage their home-related activities. On the other hand, they also described themselves as incapable and restricted as a result of frailty, lack of accessibility to the environment and social hindrances. The participants adapted and reshaped their sense of self to the new circumstances caused by frailty or external factors in a unique way. Daily life for many frail older people thus becomes more and more 
focused on the home as a place for daily activities. At home, things occur on the older people's own terms, they feel secure and can maintain their self-image as an active and capable human being despite increased dependence on other people (Fänge \& Dahlin-Ivanoff, 2009; Dahlin-Ivanoff et al., 2007). The home may thus influence the older person's functionings, since it represents a contextual factor that has an impact on their opportunities to realise their valuable goals.

Research has confirmed that independence in daily activities is strongly linked to older people's health and well-being because it can reinforce their sense of self (Haak et al., 2007). Independent performance of daily activities has therefore been used to define examples of valuable goals, or functionings, for frail older people in FRESH's studies. The instrument Canadian Occupational Performance Measure (COPM) identifies and prioritises people's valuable goals in everyday life in the areas of self-care, productivity and leisure. Even though it would be better to measure each person's valuable goals, or functionings, using a measure such as the COPM, the FRESH research group has decided to capture functionings in terms of the independent performance of daily activities.

Self-determination is another central concept when studying whether or not frail older people achieve the goals they want to achieve, and if they have the contextual conditions to live a life they consider to be good and worthy (Ottenvall Hammar et al., 2014b). The concept can be defined as a phenomenon which comprises having the ability, as well as enough knowledge and control over a whole process, to act/decide of one's own free will, and to have ethical/legal rights (Ekelund et al., 2014).

Self-determination in daily life can be assessed using the statements from the Impact on Participation and Autonomy-Older Persons (IPA-O). The IPA-O is based on self-assessment statements that capture older people's perceptions of their opportunities to decide in their daily life, such as, for example: 'My chances to help or support people in any way are good' (Ottenvall Hammar et al., 2014b). One crosssectional study using the IPA-O found that reduced self-determination in daily life was prominent among older people who were dissatisfied with their physical health. Frail older people had nearly three times higher odds of perceiving reduced selfdetermination than people who were not frail (Ottenvall Hammar et al., 2016). Thus, frail older people need support from others in their surroundings in order to exercise self-determination and to reach their valuable goals. As older people become increasingly frail and dependent on other people, they may, however, have decreased opportunities to decide for themselves about what to do, when and how. Frail older people who are in the process of losing their ability to perform the activities of daily living independently often meet numerous healthcare professionals, both in their homes and within different healthcare organisations.

Although their right to self-determination is acknowledged both in law and by professionals, studies indicate that the exercising of this right is not fully respected (Janlöv et al., 2006; Boyle, 2004). In one study (Ottenvall Hammar et al., 2014a), older people in the early stages of developing dependence on other people when performing the activities of daily living were recruited and their experiences of selfdetermination were explored. The older people experienced their self-determination 
as a process, shifting from self-governing to being governed by other people or being governed by their ageing body. Furthermore, self-determination was experienced as a struggle against their own body, in order to continue exercising selfdetermination in daily life, which in turn contributed to a feeling of being able to self-govern. Depending on the relationship between the people involved in an activity, continued self-governing in daily life was possible. Thus, decision-making in daily life was relational. Furthermore, the older people experienced a need to guard their own independence in relation to homecare services and their relatives, which gave rise to a sense of control. Freedom was sometimes beyond their opportunities. Self-determination varies over time, from actually achieving valuable goals in real life towards being ruled by others in terms of everyday life decisions (Ottenvall Hammar et al., 2014a).

To understand this divergence between the legal rights of self-determination that are acknowledged by professionals, and the fact that self-determination is still not being experienced by older people themselves, we studied the concept from two different angles. Firstly, a concept analysis, including a thorough literature review, was conducted in order to clarify the concept in relation to community-dwelling frail older people (Ekelund et al., 2014). Secondly, older people with varying degrees of frailty were asked about their experiences of the concept as described above (Ottenvall Hammar et al., 2014a). In a healthcare context, self-determination has been defined as participation in decision-making without control by others, but the two studies above (Ekelund et al., 2014; Ottenvall Hammar et al., 2014a) show that self-determination among frail older people is more complex than that. Moreover, self-determination can be threatened when the ability to independently perform daily activities is affected (Ottenvall Hammar et al., 2015). This is noteworthy because it is important for older people's health and well-being that they are allowed to make and influence decisions about their own daily lives, especially if they are dependent on others.

\subsection{The Capability Approach as a Theoretical Framework for Research with and for Frail Older People}

Viewing FRESH's research programme 'Ageing well at home', and how we conduct research, from the perspective of the capability approach, we are focusing on user involvement in research. We study the freedom needed by frail older people to decide what, when and how to do things, and we explore whether or not involvement in research on ageing and health is a valuable goal from the perspective of the frail older people themselves. Another central aspect of our research is whether and how involvement in research could increase frail older people's opportunities to lead a life they have reason to value. An important ethical starting point is that frail older people should be treated as persons who can decide for themselves and their lives, even though they are limited by frailty, morbidity and disability and are 
dependent on other people's help and support. Therefore, frail older people's own free choice has always been and still is an important area within our research programme.

As a partnership-focused programme, 'Ageing well at home' is well established in the ethical values of equality and respect. This means that we as researchers strive for transparency with regard to the aim of involving frail older people in research, what the research will lead to, and how each person can contribute to the research process with their experience, knowledge and expertise. Researchers and participants respect each other and each other's roles and perspectives and, by adapting research methods and designs, we also aim to make it possible for a diversity of different people to participate in the research. By diversity, we mean differences in age, degree of frailty and cognition, socioeconomic background, linguistic preferences, national background and experiences of, and attitudes towards, research.

Conducting research projects with and for frail older people is often a complex endeavour, with regards to both design and outcome measures, and few previous attempts have been made to include very old or very frail people in research. Understanding about how and when to conduct research together with frail older people is sparse, and even though FRESH has a strong history of involving frail older people in the research process (Dahlin-Ivanoff et al., 2010; Gustafsson et al., 2015), we still need to fill the knowledge gap with regard to frail older people's needs and desires to be involved in the research project to a greater extent than participating in an interview or filling in a survey.

Frail older people may be hard to reach out to, and they are frequently excluded from participation in research. There is a general assumption that frailty, disability and morbidity have a negative impact upon a person's ability to contribute to the research process, or that participation in research would not be beneficial for frail older people (Dewar, 2005; Ferrucci et al., 2004). Consequently, frail older people, who may also experience various degrees of disability and morbidity, have been excluded from research on ageing and health, based on the assumption that they would not have the energy to participate, or that the research would not be of benefit to them (Ferrucci et al., 2004). Linguistic differences between researchers and participants have also been used to exclude older people with experience of international migration, because the use of interpreters and translators is often an endeavour demanding substantial resources (Hussain-Gambles et al., 2004). Contextual aspects such as age, frailty and linguistic background thus seem to be important for people's real opportunities to become involved in research. There is a need for research about the complexity and diversity of desires and needs among the ageing population, with regard to both health and medical needs and the need and desire to be involved in research. Involvement in research could be used as a tool for frail older people to make their voices heard and mediate their abilities and needs, and this, in turn, could be used to improve health and social care for this segment of the population. The lack of knowledge and theoretical support for when and how frail older people could and should be involved in research has led to serious limitations on their rights to make their voices heard and have their needs met. 
Frail older people's participation in research has been described as a way for them to access care and medical examinations that they are not able to access in any other way. It is also described in relation to loyalty to the researcher who asks them to participate, and to the group of older people in general (Mein et al., 2012). Participation in research thus seems to be a way for older people to access health and social care from which they would otherwise be largely or entirely excluded. This motive for participation reveals inequities in the healthcare system, and raises the question of whether frail older people are the group with the worst access to health and social care, even though they are in most need (Townsend \& Cox, 2013; Dahlin-Ivanoff et al., 2019). To improve access to health and social care, we must first discover what needs frail older people have and what is of most importance to them. The involvement of frail older people in research could contribute to an improved understanding of their abilities and experiences, as this would allow them to contribute to the research process with their unique perspectives on what we should prioritise and how research could become more relevant to the public as the population ages (Hanson et al., 2007). Yet, many frail older people who participate in research are treated as passive informants, and the research process is entirely controlled by the researchers (Camden et al., 2015). To distribute power over the research process more equally between researchers and participating frail older people, and to work as equal partners in a joint project, we need to know more about frail older people's real opportunities. We also need to evaluate the potential challenges and pitfalls facing such work. The goal of the user involvement approach in 'Ageing well at home' is therefore to involve a broad group of people in our research, in order to counteract negative assumptions about who is capable of being involved in research.

FRESH conducts studies with and for frail older people, as well as healthcare professionals and other researchers on ageing and health. All parties are regarded as equal partners, with competence and important roles in the co-creation of knowledge. As researchers, we are experts on the research process and scientific knowledge, frail older people are experts on their own abilities and needs, and healthcare professionals are experts on what is feasible within different organisations. We do not wish to change these roles, since the value of co-creation is based on differences in perspectives and understandings. A dilemma that could arise with time is that the co-creating partnership will lead to a weaker critical mass, which means that researchers and participants may become too similar to be able to question each other. Another dilemma is the unequal division of power, with the risk that researchers' high status within many societies may impact upon frail older people's willingness and preparedness to question them or to question research-based knowledge. This influences the power relations between the two parties in the research project, which could have a negative influence on both the relationship between the researchers and participants, and the research per se. The importance of creating a trusting, tolerant and relaxed environment is highlighted, to encourage frail older people to share their experiences and knowledge. Being together with other people in a nonjudgemental and enabling environment could allow the older people to express their perspectives, and in that way to distribute the power more equitably between 
themselves and the researchers. There are also dilemmas associated with time and resources. Co-creation projects usually require a longer time for research because other people outside of academia are influencing the research process. This takes time and is complex. Contrasting this with the urge for quick results and publications could lead to difficulties with co-creation projects.

\subsection{Conclusion}

In conclusion, the purpose of this chapter was to describe how the capability approach as a theoretical framework can be applied to research on ageing well at home for frail older people. We have strived to describe the capability approach to research with and for frail older people in order to focus on the older people's opportunities to realise their goals in relation to contextual factors that may influence these opportunities. This is important because there has been criticism towards the significance of the capability approach when it comes to its application in empirical studies (Robeyns 2006), and also because knowledge regarding how the capability approach can be applied to empirical studies is sparse. Thus, instead of only assessing the health of frail older people in objective terms, the capability approach may also allow us to evaluate their opportunities to be healthy, and assess their resources to achieve their valuable goals.

To understand what is valuable and important to each person, one must start with a conversation, a dialogue, where people are seen as equal, and where everyone can contribute with knowledge that is considered valuable. This means that frail older people must be given the opportunity to express what is important to them, and how they want things to be done. It also entails that frail older people need to be given opportunities to be involved in decision-making, and to exercise self-determination in daily life when they want to. When assessing ageing well at home, the capability approach could be a possible way to focus on what older people are effectively able to do and be, when considering contextual factors as well as individual choice (Sen, 1985). Our research programme 'Ageing well at home' illustrates the need to recognise each person's capabilities, because it can mean the difference between success and failure in attaining valued goals in life. Despite there being an instrument (COPM) that identifies and prioritises valuable goals in everyday life, we have not so far assessed each person's level of valuable goals (functionings). Based on earlier qualitative research, and by assessing ADL, we do however capture functionings at a general level, even though it would be better if we measured each person's valuable goals (functionings).

In summary, the core of what we do is to promote frail older people's real opportunities to do and be what they have a reason to value. We have conducted several qualitative studies and the results have given a picture of the real opportunities people achieve. This chapter could be a stepping-stone for future researchers to consider evaluating and implementing the capability approach into their research. 


\section{References}

Blasimme, A. (2017). Physical frailty, sarcopenia, and the enablement of autonomy: Philosophical issues in geriatric medicine. Aging Clinical and Experimental Research, 29, 59-63.

Boyle, G. (2004). Facilitating choice and control for older persons in long-term care. Health \& Social Work, 12, 212-220.

Camden, C., Shikako-Thomas, K., Nguyen, T., Graham, E., Thomas, A., Sprung, J., Morris, C., \& Russell, D. (2015). Engaging stakeholders in rehabilitation research: A scoping review of strategies used in partnerships and evaluation of impacts. Disability and Rehabilitation, 37, $1390-1400$.

Clegg, A., Young, J., Ilie, S., Rikkert, M., \& Rockwood, K. (2013). Frailty in elderly people. Lancet, 381, 752-762.

Dahlin-Ivanoff, S., Haak, M., Fänge, A., \& Iwarsson, S. (2007). The multiple meaning of home as experienced by very old Swedish people. Scandinavian Journal of Occupational Therapy, $14,25-32$.

Dahlin-Ivanoff, S., Gosman-Hedström, G., Edberg, A.-K., Wilhelmson, K., Eklund, K., Duner, A., Zidén, L., Welmer, A.-K., \& Landahl, S. (2010). Elderly persons in the risk zone: Design of a multidimensional, health-promoting, randomised three-armed controlled trial for 'prefrail' people of 80+ years living at home. BMC Geriatrics, 10, 27.

Dahlin-Ivanoff, S., Rydberg Sterner, T., Blennow, K., Skoog, I., \& Falk Erhag, H. (2019). Was it worth it? Older adults' experiences of participating in a population-based cohort study: A focus group study. BMC Geriatrics, 19, 224.

Dewar, B. (2005). Beyond tokenistic involvement of older people in research: A framework for future development and understanding. Journal of Clinical Neuroscience, 14, 48-53.

Ebrahimi, Z., Wilhelmson, K., Eklund, K., Moore, C., \& Jakobsson, A. (2013). Health despite frailty: Exploring influences on frail older adults' experiences of health. Geriatric Nursing, 34, 289-294.

Ebrahimi, Z., Dahlin-Ivanoff, S., Eklund, K., Jakobsson, A., \& Wilhelmson, K. (2015). Self-rated health and health strengthens factors in community living frail elders. Journal of Advanced Nursing, 71, 825-836.

Ekelund, C., Dahlin-Ivanoff, S., \& Eklund, K. (2014). Self-determination and older persons: A concept analysis. Scandinavian Journal of Occupational Therapy, 21, 116-124.

Fabbri, E., Zoli, M., Gonzalez-Freire, M., Salive, M., Studenski, S., \& Ferrucci, L. (2015). Aging and multimorbidity: New tasks, priorities, and frontiers for integrated gerontological and clinical research. Journal of the American Medical Directors Association, 16, 640-647.

Fänge, A., \& Dahlin-Ivanoff, S. (2009). The home is the hub of health in very old age: Findings from the ENABLE-AGE project. Archives of Gerontology and Geriatrics, 48, 340-345.

Ferrucci, L., Guralnik, J., Studenski, S., Fried, L., Cutler, G., \& Walston, J. (2004). Designing randomized, controlled trials aimed at preventing or delaying functional decline and disability in frail, older persons: A consensus report. Journal of the American Geriatrics Society, 52, 625-634.

Fried, L., Tangen, C., Walston, J., Newman, A., Hirsch, C., Gottdiener, J., Seeman, T., Tracy, R., Kop, W., Burke, G., \& McBurnie, M. (2001). Frailty in older adults: Evidence for a phenotype. The Journals of Gerontology, 56, M146-M156.

Fried, L., Ferrucci, L., Darer, J., Williamson, J., \& Anderson, G. (2004). Untangling the concepts of disability, frailty, and comorbidity: Implications for improved targeting and care. The Journals of Gerontology: Series A, Biology, 59, 255-263.

Fulop, T., Larbi, A., Witkowski, J., McElhaney, J., Loeb, M., Mitnitski, A., \& Pawelec, G. (2010). Aging, frailty and age-related diseases. Biogerontology, 11, 547-563.

Gustafsson, S., Lood, Q., Wilhelmson, K., Häggblom-Kronlöf, G., Landahl, S., \& Dahlin-Ivanoff, S. (2015). A person-centred approach to health promotion for persons $70+$ who have migrated to Sweden: Promoting aging migrants' capabilities implementation and RCT study protocol. BMC Geriatrics, 15, 10. 
Haak, M., Fänge, A., Iwarsson, S., \& Dahlin-Ivanoff, S. (2007). Home as a signification of independence and autonomy: Experiences among very old Swedish people. Scandinavian Journal of Occupational Therapy, 14, 16-24.

Häggblom-Kronlöf, G., Hultberg, J., Eriksson, B., \& Sonn, U. (2007). Experiences of daily occupations at 99 years of age. Scandinavian Journal of Occupational Therapy, 14, 192-200.

Hanson, E., Magnusson, L., Arvidsson, H. A. K., Keady, J., \& Nolan, M. (2007). Working together with persons with early stage dementia and their family members to design a user-friendly technology-based support service. Dementia: The International Journal of Social Research and Practice, 6, 411-434.

Hogan, D., MacKnight, C., \& Bergman, H. (2003). Models, definitions, and criteria of frailty. Aging Clinical and Experimental Research, 15, 1-29.

Hussain-Gambles, M., Atkin, K., \& Leese, B. (2004). Why ethnic minority groups are underrepresented in clinical trials: A review of the literature. Health \& Social Care in the Community, $12,382-388$.

Janlöv, A., Hallberg, I., \& Petersson, K. (2006). Older persons' experience of being assessed for and receiving public home help: Do they have any influence over it? Health \& Social Care in the Community, 12, 26-36.

Lally, F., \& Crome, P. (2007). Understanding frailty. Postgraduate Medical Journal, 83, 16-20.

Mein, G., Seale, C., Rice, H., Johal, S., Ashcroft, R., Ellison, G., \& Tinker, G. (2012). Altruism and participation in longitudinal health research? Insights from the Whitehall II study. Social Science \& Medicine, 75, 2345-2352.

Morley, J., Vellas, B., Van Kan, G., Anker, S., Bauer, J., Bernabei, R., Cesari, M., Chumlea, W., Doehner, W., Evans, J., Fried, L., Guralnik, J., Katz, P., Malmstrom, T., McCarter, R., Guiterrez Robledo, L., Rockwood, K., Von Haehling, S., Vandewoude, M., \& Walston, J. (2013). Frailty consensus: A call to action. Journal of the American Medical Directors Association, 14, 392-397.

Ottenvall Hammar, I., Dahlin-Ivanoff, S., Wilhelmson, K., \& Eklund, K. (2014a). Shifting between self-governing and being governed: A qualitative study of older persons' self-determination. BMC Geriatrics, 14, 126.

Ottenvall Hammar, I., Ekelund, C., Wilhelmson, K., \& Eklund, K. (2014b). Impact on participation and autonomy: Test of validity and reliability for older persons. Health Psychology, 2, 68-73.

Ottenvall Hammar, I., Dahlin-Ivanoff, S., Wilhelmson, K., \& Eklund, K. (2015). People dependent on support in daily activities perceives reduced self-determination: A cross-sectional study with community-dwelling older persons. Quality in Ageing, 16, 208-221.

Ottenvall Hammar, I., Dahlin-Ivanoff, S., Wilhelmson, K., \& Eklund, K. (2016). Self-determination among community-dwelling older persons: Explanatory factors. Scandinavian Journal of Occupational Therapy, 23, 198-206.

Reuben, D. (1998). Warning signs along the road to functional dependency. Annals of Internal Medicine, 128, 138-139.

SBU. (2014). Comprehensive geriatric assessment and care of frail elderly (SBU report no 221 (in Swedish)). SBU.

Sen, A. (1985). Well-being, agency and freedom: The Dewey lectures 1984. Journal of Philosophy, $82,169-221$.

Sen, A. (1993). Capability and Well-being. In M. Nussbaum \& A. Sen (Eds.), The quality of life (pp. 1-30). Clarendon Press.

Sonn, U. (1996). Longitudinal studies of dependence in daily life activities among elderly persons. Scandinavian Journal of Rehabilitation Medicine. Supplement, 34, 1-35.

Townsend, A., \& Cox, S. (2013). Accessing health services through the back door: A qualitative interview study investigating reasons why people participate in health research in Canada. BMC Med Ethics, 14(40), Web. 
Open Access This chapter is licensed under the terms of the Creative Commons Attribution 4.0 International License (http://creativecommons.org/licenses/by/4.0/), which permits use, sharing, adaptation, distribution and reproduction in any medium or format, as long as you give appropriate credit to the original author(s) and the source, provide a link to the Creative Commons license and indicate if changes were made.

The images or other third party material in this chapter are included in the chapter's Creative Commons license, unless indicated otherwise in a credit line to the material. If material is not included in the chapter's Creative Commons license and your intended use is not permitted by statutory regulation or exceeds the permitted use, you will need to obtain permission directly from the copyright holder. 